\title{
Effect of Severe Temperatures and Restraint on Instability and Buckling of Elliptical Steel Columns
}

\author{
F. Ali*, A. Nadjai \\ FireSERT, School of the Built Environment, University of Ulster, Newtownabbey, UK \\ Email: ^f.ali@ulster.ac.uk
}

How to cite this paper: Ali, F. and Nadjai, A. (2018) Effect of Severe Temperatures and Restraint on Instability and Buckling of Elliptical Steel Columns. Open Journal of Civil Engineering, 8, 41-57.

https://doi.org/10.4236/ojce.2018.81004

Received: January 12, 2018

Accepted: March 6, 2018

Published: March 9, 2018

Copyright (c) 2018 by authors and Scientific Research Publishing Inc. This work is licensed under the Creative Commons Attribution International License (CC BY 4.0).

http://creativecommons.org/licenses/by/4.0/

\section{(c) (i) Open Access}

\begin{abstract}
This paper presents the findings of an experimental research to investigate the performance of axially restrained elliptical hollow (EHS) steel columns subjected to severe hydrocarbon fire. The test programme involved 12 steel columns presenting 2 oval sections $200 \times 100 \times 8 \mathrm{~mm}$ and $300 \times 150 \times 8 \mathrm{~mm}$ and yielding 2 slenderness $\lambda=51$ and 33. The $1800 \mathrm{~mm}$ columns were tested under loading ratios ranging between 0.2 and 0.6 of the ultimate strength determined using EC3 and under axial restraint degree ranging from 0 to 0.16 . The obtained results of axial displacements, lateral displacements, measured restraint forces, and high temperatures are presented in the paper. It was found that introducing restraint to the columns with elliptical section produces high restraint forces which reduce the time to lose lateral stability. This is more evident in cases of lower load ratios than the higher load ratios. The numerical study presented in this paper involved building a finite element model to simulate the columns behaviour in fire. The model was validated using the test results obtained from unrestrained and restrained columns fire tests. The model demonstrated good agreement in the prediction of failure times and failure mechanisms of local and overall buckling. The FEM model was then used to conduct a parametric analysis involving factors of slenderness, restraint and loading. The conclusions drawn for this research are presented at the end of the paper.
\end{abstract}

\section{Keywords}

Elliptical, Columns, Steel, Fire, Restraint, Buckling

\section{Introduction}

In spite of the increasing use of elliptical hollow steel sections in buildings (due 
to their aesthetically pleasing shape compared to rectangular and circular hollow sections), there are limited researches carried out on the performance of columns with elliptical sections under fire conditions especially with axial restraint. The growing trend in the construction industry to use elliptical hollow steel sections in buildings requires more research investigating the performance of structural elements with elliptical sections. There is however very limited research carried out on the performance of the elliptical columns under fire conditions especially with introduction restraint boundary conditions. In recent years, research has investigated the performance of other hollow sections available (circular, rectangular and square) under loading and fire conditions. There have been some researches carried out on the performance of stub elliptical columns under loading conditions by Gardner et al. [1] [2] and [3] and Chan et al. [4] for hollow sections under room temperatures which involved testing and using an ABAQUS validated finite element model that was used in parametric studies giving rise to guidance on the section classification. Following on from this, Zhu et al. [5] modelled the stub sections in order to predict an equivalent circular hollow section to provide an understanding of the local buckling behaviour observed in the elliptical sections. However, these researches on elliptical sections focused on behaviour under room temperatures. A limited number of researches under high temperatures were carried out by Scullion et al. [6] and [7] on hollow elliptical sections and some other researches were carried out on concrete filled elliptical columns by Ali et al. [8] and by Espinos et al. [9] [10] who used the Finite Element Method to study the behaviour of concrete filled elliptical sections in fire. It is obvious from the available literature that there is a very limited research carried out on hollow elliptical sections under fire situations in general. In addition, the performed research on EHS under room temperature has contributed to understanding their behaviour and also assisted in formulating design guidelines for structural engineers. However, as mentioned, majority of the previous researches had studied the behaviour of EHS at room temperatures and no experimental research was dedicated to study the performance of restrained EHS in fire situations. This has created a gap in the fire safety standards of civil and industrial buildings for this type of structural elements. In order to address this niche, the work presented in this paper was conducted. The scarce number of fire tests on EHS has motivated the investigators to conduct this research. The objectives of this paper are to present the outcomes of experimental and numerical study on the behaviour of 12 steel columns with elliptical sections focusing on lateral instability. The test programme has been designed to investigate factors that can influence the fire performance of elliptical columns including slenderness, load ratio and axial restraint. The columns were subjected to the hydrocarbon fire curve shown in Ali et al. [8] which is taken from EC1 [11], with the ultimate strength of the columns calculated using EC3 [12] and [13]. The paper also includes a parametric finite element study where the validated model was used to study the effect of factors including loads, restraint, and slenderness. 


\section{The Experimental Programme}

Twelve elliptical steel columns were tested at the FireSERT research laboratories at the University of Ulster. The rig (see Figure 1) used during testing allows for loads to be applied to the columns and can provide axial restraint using the rig stiffness. The facilities also allow, measuring thermocouple temperature readings, axial and lateral displacements using LVDT's. The test programme involved testing columns with 2 oval sections $200 \times 100 \times 8 \mathrm{~mm}$ (EHS-A) and 300 $\times 150 \times 8 \mathrm{~mm}(\mathrm{EHS}-\mathrm{B})$ of length $=1800 \mathrm{~mm}$, yielding 2 slenderness $\lambda=51$ and 33. The columns were tested under loadings levels of $0.2,0.4$ and 0.6 of the ultimate strength for the hollow elliptical section EC3 [12] [13] under axial restraint $\alpha_{k}$ ranging from 0 to 0.16 . The degree of axial restraint $\alpha_{k}$ is defined as:

$$
\alpha_{k}=\frac{K_{s}}{K_{c}}
$$

where $K_{s}$ is the stiffness of the surrounding structure (rig), $K_{c}$ is the axial stiffness of the column

$$
K_{c}=\frac{A E}{L}
$$

where $A$ is the column section area; $E$ is the Young modulus and $L$ is the length of the column. The loading imposed on columns was increased gradually in equal time steps to allow the column to settle and to get stable readings. Once the load level was reached the burner was ignited subjecting the columns to a hydrocarbon fire Ali et al. [8]. The columns were with pin ended supports at the top and the bottom by using half-moon steel bearings at each end. To reduce the friction at the supports, graphite tape was incorporated between the two steel surfaces to provide lubrication. The thermocouples were located throughout the length of the column to measure the temperatures at $250 \mathrm{~mm}$ from the top and $250 \mathrm{~mm}$ from the bottom of the column as well as at the mid height of the column. Four thermocouples were placed around the outside of the column as shown in Figure 1.
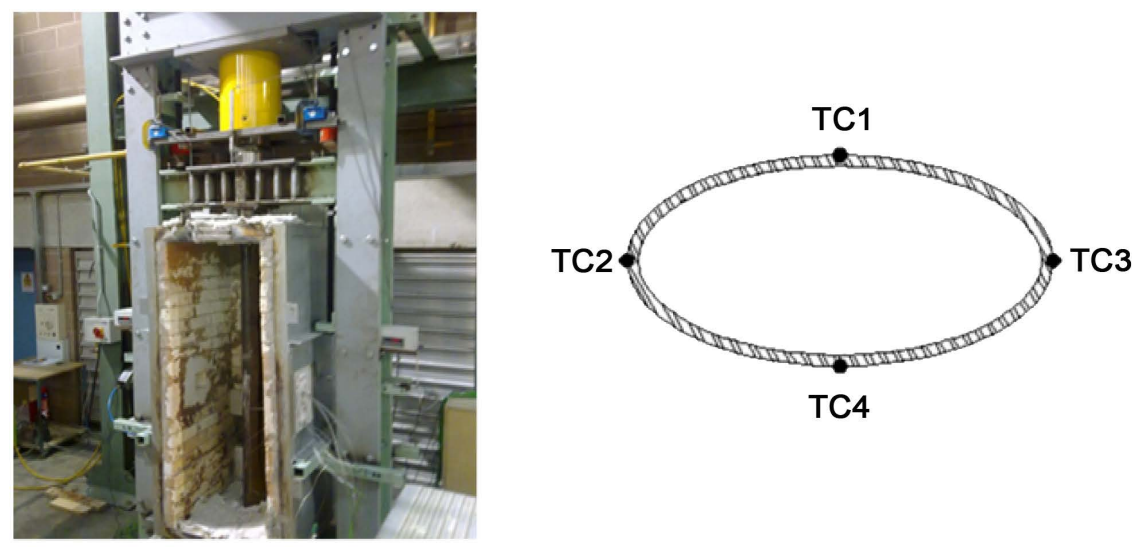

Figure 1. (Left) Testing rig, (Right) Thermocouple locations for the elliptical steel columns. 
The testing rig is shown in Figure 1 where LVDT's displacement sensors were used to measure the axial displacement at the top of the column at the front and back and also at the bottom of the test rig and the average values were calculated. In order to measure the lateral displacement of the columns, quartz rods were used (due to their small thermal expansion) and placed through the side of the furnace touching the surface of the column with the other end connected to LVDT outside the furnace. The restraint was provided by the stiffness of the testing rig and the use of rubber springs. In order to apply the required restraint, special mounted nuts were tightened on the threaded bars on either side of the furnace. Load cells were used to measure applied load and restraint forces.

\section{Test Results}

\subsection{Unrestrained Elliptical Columns}

The data of axial and lateral displacements obtained from the tests are shown in Figure 2 for EHS-A (slenderness $\lambda=51$ ) and Figure 3 for EHS-B (slenderness $\lambda$ =33). The results for column EHS-A show that as the load ratio is increased the time for loosing lateral stability drops from $13 \mathrm{mins}$ for 0.2 loading, to $10 \mathrm{mins}$ for 0.4 and to $8 \mathrm{mins}$ for 0.6 loading. The same relationship can be seen from the results for the EHS-B where the time of failure by losing lateral stability drops from $13 \mathrm{mins}$ for 0.2 loading, to $10 \mathrm{mins}$ for 0.4 to $8 \mathrm{~min}$ for 0.6 loading.

By comparing the two sets of data, it can be seen that the columns responded to heating in a similar way as the axial displacement increased linearly as the time increased. When the column reached the maximum axial displacement it started to fail slowly at first (due to degradation in the steel properties under high temperatures), then the deformation started to increase more rapidly towards complete failure. This can be observed more clearly in the load levels of 0.6 of the ultimate loading as there are approximately 30 seconds between the peak deformation and the columns failure where as it takes the 0.2 loaded columns between approximately $1 \mathrm{~min} 30 \mathrm{secs}$ to $2 \mathrm{mins}$. The results show that the
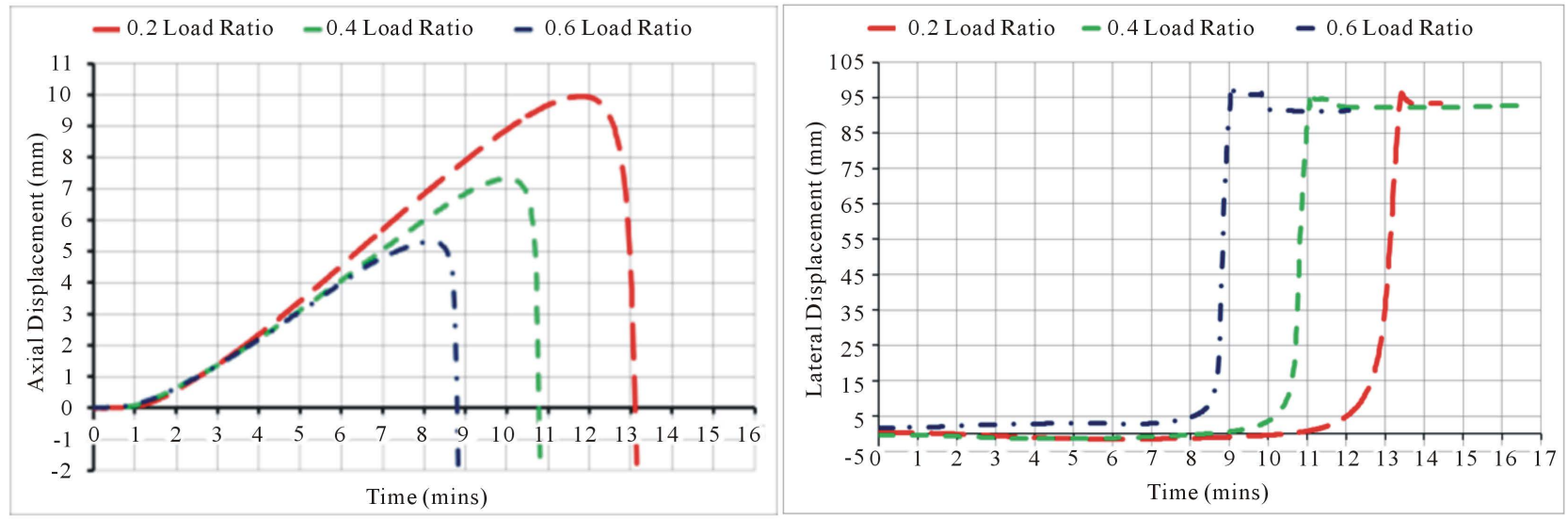

Figure 2. Development of lateral and axial displacements for unrestrained columns $200 \times 100 \times 8$ (EHS-A), (left) axial displacement, (right) lateral displacement. 

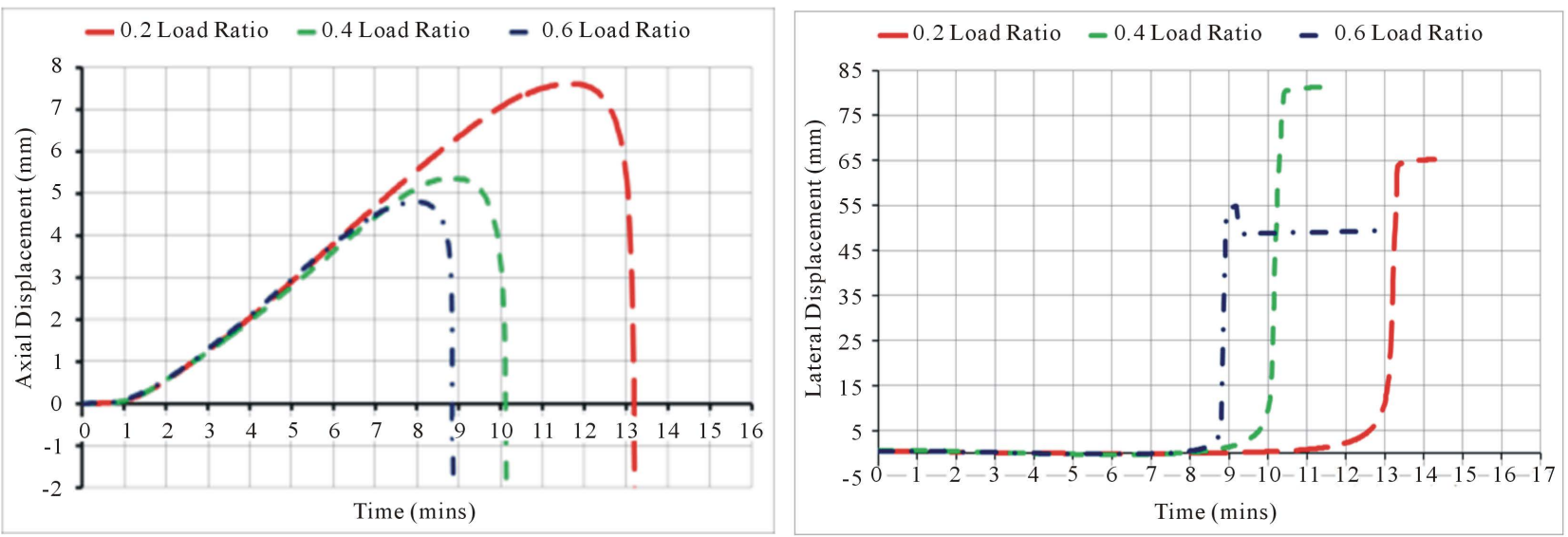

Figure 3. Development of lateral and axial displacements for unrestrained columns $300 \times 150 \times 8$ EHS-B, (left) axial displacement. (right) Lateral displacement.

two sections demonstrated the same fire resistance time for each of the different loading levels regardless of the size of the section. Figure 2 and Figure 3 show a consistent correspondence between the development of lateral and axial displacements under high temperatures.

\subsection{Restrained Elliptical Columns}

In the case of the restraint tests the same load ratios of $0.2,0.4$ and 0.6 were applied to the columns as in the unrestrained tests. The restraint provided during the tests was imposed by the stiffness of the testing rig with the addition of rubber springs which help to provide a range of rig stiffness (Figure 4).

The displacements obtained during the tests show that the EHS-AR (slenderness $\lambda=51$ ) failure time (due to loosing lateral stability) decreases with the increase of loading level from 10mins for 0.2 , to 8 mins for 0.4 and to 6 mins for 0.6 (Figure 5).

The same relationship can be seen in the larger EHS-BR (slenderness $\lambda=33$ ) section, 10 mins for 0.2 , to 9 minutes for 0.4 and to 8 minutes for 0.6 (Figure 6). It can be observed from the data that the time to failure from the point of maximum axial displacement increases with the rise in the load ratio applied to the section due to the frictional forces generated at the supports.

The results indicate that the failure by losing lateral stability of the EHS-BR tests occurs gradually when the load ratio increases if compared with the smaller EHS-AR section. This can be attributed to the high frictional forces being generated at the half moon supports for the larger sections as the load applied is greater than that of the smaller section. As both of the sections were subjected to relatively the same axial restraint then this may be a feasible reason for this observation.

\subsection{Tests Summary}

In each of the tests the lateral displacements of the columns were recorded using 

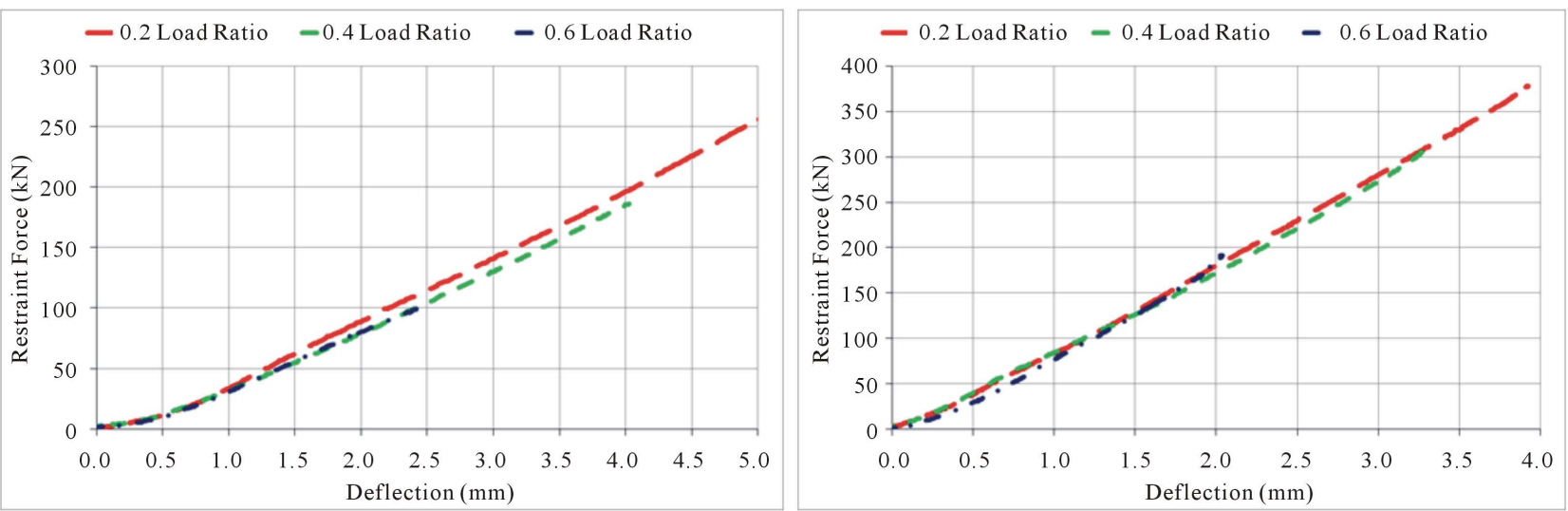

Figure 4. Restraint forces vs. displacement for restraint tests, (left) EHS-AR (slenderness $\lambda=51$ ), (right) EHS-BR (slenderness $\lambda=$ 33).
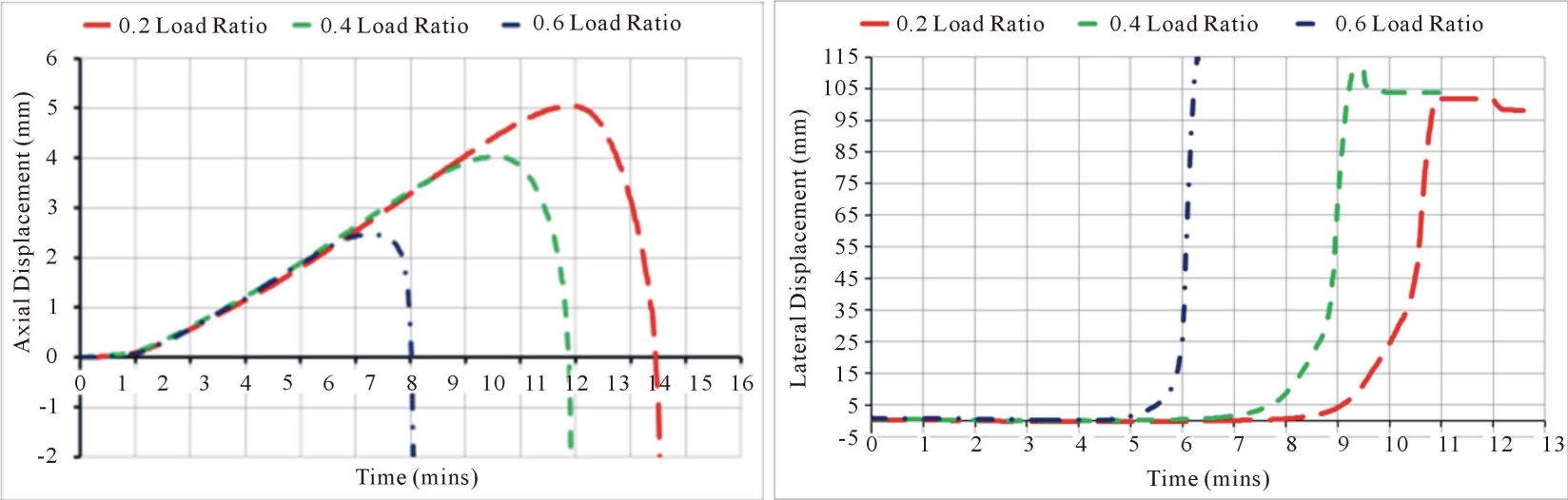

Figure 5. Development of lateral and axial displacement for restrained columns $200 \times 100 \times 8$ EHS-AR, (left) axial displacement, (right) lateral displacement.
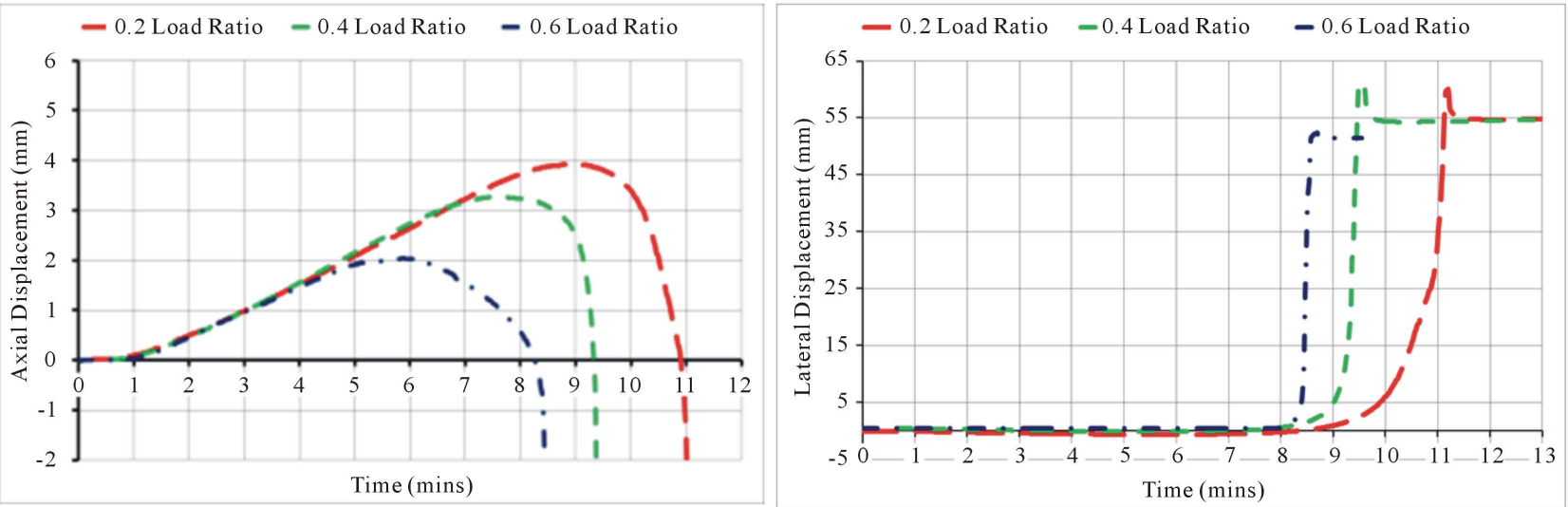

Figure 6. Development of lateral and axial displacement for restrained columns $300 \times 150 \times 8$ EHS-BR (slenderness $\lambda=33$ ), (left) axial displacement, (right) lateral displacement.

quartz rods connected to the LVDTs. The columns are deemed to have failed laterally when the column has deflected by more than L/300, according to the EC3 [12] which in this case is $6 \mathrm{~mm}$. The second failure criteria adopted is when 
the column falls below the datum zero line recoded before heating and after loading. The results of both failure criteria and axial displacements of the unrestrained columns are shown in Table 1.

In general the restrained columns demonstrated lower fire resistance than the unrestrained columns and the results are shown in Table 2. It is important to emphasize that the two adopted failure criteria of lateral and axial displacements converge under high loadings.

When comparing the overall buckling and local buckling failure mechanisms shown in Figure 7 it can be seen that both sections failed in a similar mode, regardless of the degree of axial restraint imposed on the column, with some difference in the local failure which can be attributed to the classification of the section. As the EHS-B is classified as a slender section it is deemed to be more susceptible to localised buckling than in that of the compact EHS-A.

\section{The Finite Element Model}

\subsection{Temperature Analysis}

The elliptical columns were modelled using the finite element method and the software Diana TNO [14]. The program is capable of a wide range of calculation aspects which includes thermal and structural analysis. In analysing the thermal

Table 1. Summary of unrestrained columns test results for elliptical columns.

\begin{tabular}{|c|c|c|c|c|c|}
\hline \multirow{2}{*}{ Section } & \multirow{2}{*}{ Load Ratio } & \multirow{2}{*}{ Load $(\mathrm{kN})$} & \multicolumn{2}{|c|}{ Time to Failure (mins) } & \multirow{2}{*}{ Maximum Axial Displacement (mm) } \\
\hline & & & Axial & Lateral & \\
\hline \multirow{3}{*}{$\begin{array}{c}200 \times 100 \times 8 \\
\text { EHS-A }\end{array}$} & 0.2 & 212 & 13 & 11 & 9.94 \\
\hline & 0.4 & 424 & 10 & 10 & 7.31 \\
\hline & 0.6 & 616 & 8 & 7 & 5.31 \\
\hline \multirow{3}{*}{$\begin{array}{c}300 \times 150 \times 8 \\
\text { EHS-B }\end{array}$} & 0.2 & 354 & 13 & 12 & 7.61 \\
\hline & 0.4 & 701 & 10 & 9 & 5.36 \\
\hline & 0.6 & 1053 & 8 & 8 & 4.81 \\
\hline
\end{tabular}

Table 2. Summary of restrained columns test results for elliptical columns.

\begin{tabular}{|c|c|c|c|c|c|c|c|}
\hline \multirow{2}{*}{ Section } & \multirow{2}{*}{$\begin{array}{l}\text { Load } \\
\text { Ratio }\end{array}$} & \multirow{2}{*}{$\begin{array}{l}\text { Degree of Axial } \\
\text { Restraint } \alpha_{k}\end{array}$} & \multirow{2}{*}{ Load $(\mathrm{kN})$} & \multicolumn{2}{|c|}{ Time to Failure (mins) } & \multirow{2}{*}{$\begin{array}{l}\text { Maximum Axial } \\
\text { Displacement } \\
(\mathrm{mm})\end{array}$} & \multirow{2}{*}{$\begin{array}{c}\text { Maximum } \\
\text { Restraint Force } \\
(\mathrm{kN})\end{array}$} \\
\hline & & & & Axial & Lateral & & \\
\hline \multirow{3}{*}{$\begin{array}{c}200 \times 100 \times 8 \\
\text { EHS-AR }\end{array}$} & 0.2 & & 209 & 10 & 8 & 5.04 & 257.032 \\
\hline & 0.4 & 0.12 & 411 & 8 & 7 & 4.04 & 186.066 \\
\hline & 0.6 & & 637 & 5 & 5 & 2.47 & 100.745 \\
\hline \multirow{3}{*}{$\begin{array}{c}300 \times 150 \times 8 \\
\text { EHS-BR }\end{array}$} & 0.2 & & 348 & 10 & 9 & 3.93 & 378.191 \\
\hline & 0.4 & 0.16 & 697 & 9 & 8 & 3.27 & 305.585 \\
\hline & 0.6 & & 1052 & 8 & 8 & 2.04 & 191.431 \\
\hline
\end{tabular}




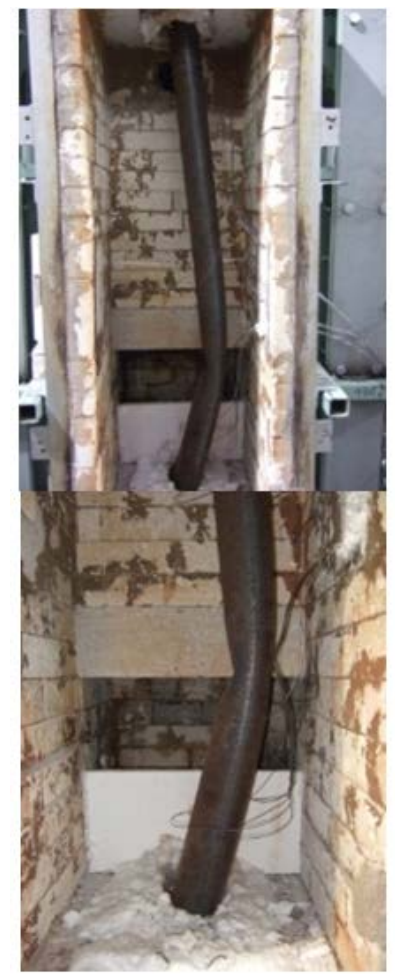

(a)

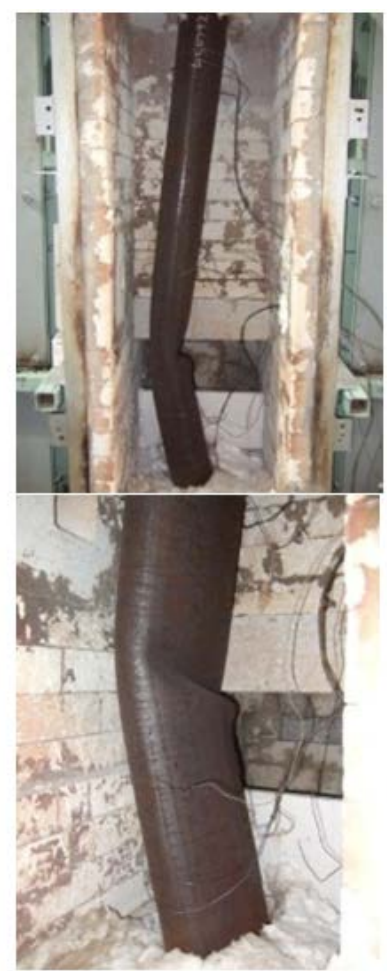

(b)

Figure 7. Failure modes of overall and local buckling of the elliptical hollow sections. (a) EHS-A (slenderness $\lambda=51$ ); (b) EHS-B (slenderness $\lambda=33$ ).

response of the columns, a transient heat transfer analysis was performed using a three-dimensional steady-state heat flow derived for the Law of Conservation of Energy:

$$
\frac{\delta}{\delta x}\left(k \frac{\delta T}{\delta x}\right)+\frac{\delta}{\delta y}\left(k \frac{\delta T}{\delta y}\right)+\frac{\delta}{\delta z}\left(k \frac{\delta T}{\delta z}\right)+Q-\rho c \frac{\delta T}{\delta t}=0
$$

where: $k$ is the thermal conductivity; $T$ is the temperature gradient; $Q$ is the internally generated heat per unit volume per unit time, $\rho$ is the density of the material; $c$ is the specific heat of the material and $t$ is time. Solution of Equation (3) is governed by the boundary condition:

$$
-k \frac{\delta T}{\delta n}=h_{c}\left(T_{s}-T_{f}\right)+h_{r}\left(T_{s}-T_{f}\right)
$$

where: $n$ is the direction of heat flux; $h_{c}$ is the heat transfer coefficient; $T_{s}$ is the temperatures of the solid surface, $T_{f}$ is the temperatures of the fluid and $h_{r}$ is the radiation heat transfer coefficient calculated using Stefan-Boltzmann equation.

The Galerkin method was used by determining $\{T\}$ as a function of time and expressed as the first order differential equation:

$$
[k]\left\{T_{n}\right\}+[c]\left\{T_{n}\right\}=\left\{F_{n}\right\}
$$

where: $[k]$ is element heat conduction/convection matrix; $[c]$ is element heat capacity matrix; $\left\{T_{n}\right\}$ is element nodal temperature vector; $\left\{F_{n}\right\}$ is element nodal 
heat input vector and defined at boundary nodes using Equation (6):

$$
-k\left[\frac{\delta T}{\delta x} l_{1}+\frac{\delta T}{\delta x} m_{1}\right]=h_{c}\left[T_{e}-T_{r}\right]+\varepsilon_{e} \sigma\left[T_{e}^{4}+T_{r}^{4}\right]
$$

where: $T_{e}=$ temperature of emitting surface; $T_{r}=$ temperature of surface; $s=$ Stefan-Boltzmann coefficient; $I_{1}$-direction cosine of $n$ relative to $x=\cos \theta, m_{1}=$ direction cosine of $n$ relative to $y=\sin \theta, \mathcal{E}_{\mathrm{e}}=$ emissivity of the surface.

\subsection{Structural Analysis}

After completing the thermal analysis, the model undergoes structural analysis to evaluate the effect of temperatures on the column behaviour. The stresses that occur under temperature are governed by the following equation:

$$
\{\sigma\}=[K]\left\{\varepsilon-\varepsilon_{T}\right\}
$$

where: $\{\sigma\}=$ stress vector; $[K]=$ stiffness matrix; $\mathcal{E}_{\mathrm{T}}=$ thermal strain vector.

\subsection{Model's Materials}

In order to calculate the stiffness matrix $[K]$ in Equation (7) a material model was assigned to the structural element. In the case of the elliptical section it is taken as steel material with a yield stress value $355 \mathrm{~N} / \mathrm{mm}^{2}$, and a standard stress/strain curve was adapted with the Von-mises failure criteria used. The non-linear properties of the steel are taken from EC3 (2005a, 2005b) for the change due to high temperatures.

\subsection{The Built Model}

A 3-D model was created for the two elliptical sections, $200 \times 100 \times 8 \mathrm{~mm}$ and $300 \times 150 \times 8 \mathrm{~mm}$. The structural model consists of a 20 node of iso-parametric brick element, CHX60, TNO [14] with three degrees of freedom and allow the calculation of stresses and strains through the volume of the element using a $3 \times$ $3 \times 3$ integration system based on Gauss integration. The boundary heated element, BQ4HT, which is a four-node iso-parametric quadrilateral element was used to define the boundaries in three-dimensional general potential flow analysis TNO [14]. During the analysis stage the twenty-node iso-parametric brick element was merged with the 4 nodes of the three-dimensional (3D) linear boundary flow element.

A sensitivity analysis was carried out in order to determine the size of the meshing to be used that would enable fast computational time without compromising the performance of the model. The final model created consisted of 38,845 nodes and 10,445 elements that represent the structural and temperature elements as shown in Figure 8. The top support for the column is allowed to rotate freely in all directions and to translate in the $\mathrm{Z}$ direction to allow the column to expand. The bottom support condition allows for rotation in all directions and restrains the nodes from any translation in all directions. 


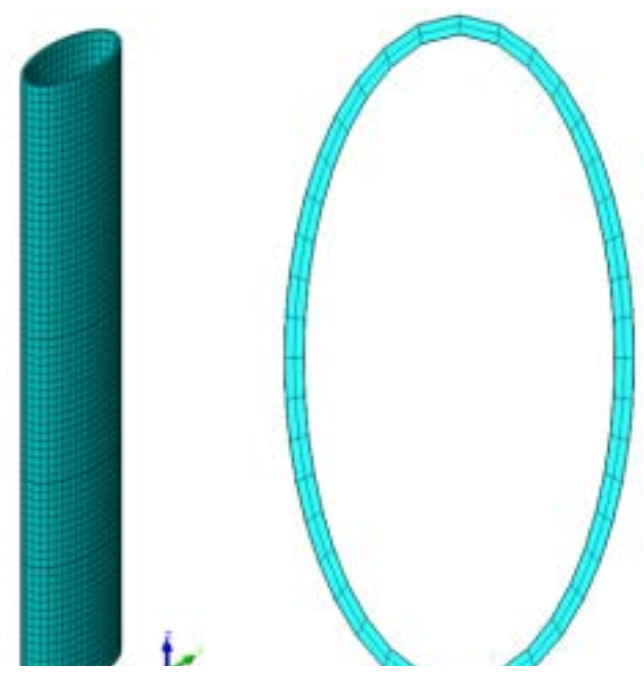

Figure 8. FEM created for the elliptical sections.

The room temperature compressive capacity of the model was first validated using the EC3 [12] [13], before a structural thermal analysis was commenced. The numerical analysis was performed using a staggered transient heat-flow stress path. The built model considered thermal conduction and radiation heat transfer. The heat transfer analysis produced nodal temperature readings which were used in the structural analysis to determine the reduction in the yield strength and stiffness of the steel material properties according to EC3 [13]. Before performing the structural nonlinear analysis the model underwent a structural stability check that involves an Eigenvalue analysis taking into account imperfections and loading eccentricities. This produces predicted buckling failure modes that will occur either by local, overall buckling or a combination of both. The temperature values resulting from the heat flow analysis are then tabulated into a time-temperature form, and used for the structural analysis. The nonlinear structural analysis is run with Newton Modified method with line search algorithm.

\subsection{Axial Restraint}

In the case of considering axial restraint, the restraint was modelled using a one way spring with constant stiffness to simulate the effect of surrounding structural elements in practice. The restraint is formed by using a $0 \mathrm{D}$, one node element in the form of a discrete spring/dashpot element, SP1TR, whereby the total restraint applied is the total number of nodes times the individual spring stiffness of each node.

The model allows for the loading and unloading of the spring to occur (Figure 9) so as to accommodate the mechanical loading on the column. This was specified in the analysis by establishing two spring diagrams one of which is where there is no spring present and the other representing the stiffness of the surrounding structure. 


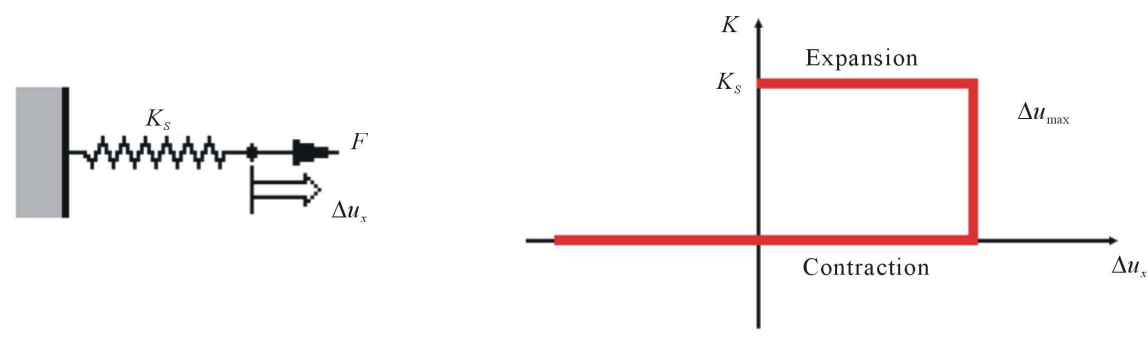

Figure 9. Spring unloading and reloading used in modelling.

\section{Validation of the Finite Element Model}

\subsection{Unrestrained Columns}

The output from the modelling provides detailed predictions on the temperature and deformation of the sections over the period that is exposed to the fire. Figure 10 shows that for the EHS-A the FEM results are in good agreement with the tests with regards to the failure time and the maximum displacement. The only exception was a slight divergence noticeable on the displacement domain; however agreement was obtainable in the failure time domain.

The FEM results for the EHS-B are also in good agreement in failure times for the 0.4 and 0.6 load ratios whereas for the 0.2 load ratio the model slightly over predicts the failure time as shown in Figure 10. There is some divergence in the prediction of axial deformation as there is an overestimation for the 0.2 and 0.4 models and an underestimation for the 0.6 model.

The results of the lateral displacements produced by the FEM are shown in Figure 11. The results indicate that the model successfully predicts the failure time by losing lateral stability and run-away status. The accuracy of the model is reasonably good with some slight divergence mainly in the higher slenderness sections. This can be attributed to the fact that the model has not taken into account frictional forces that may have been generated at the supports during the experimental tests which may explain the slight difference in failure times.

The failure of the EHS-A in the tests was mainly due to the overall buckling of the columns with occurrence of local buckling as can be seen in Figure 12. This figure shows that the FE model, of the columns has produced remarkable agreement with the tests failure mode for both of the overall and local buckling. The failure mechanism that was observed in the testing was generally overall buckling of the elliptical columns. However with the EHS-B sections there is evidence of local buckling occurring also at the failure point along with overall buckling. There is further evidence by looking at the failure of the columns in the FEM which show the failure occurring at the same point in the test and some localised buckling has been observed.

\subsection{Restrained Columns}

The column models were subjected to a restraining force which represents the surrounding structure which in this case is the testing rig. The summary of the 

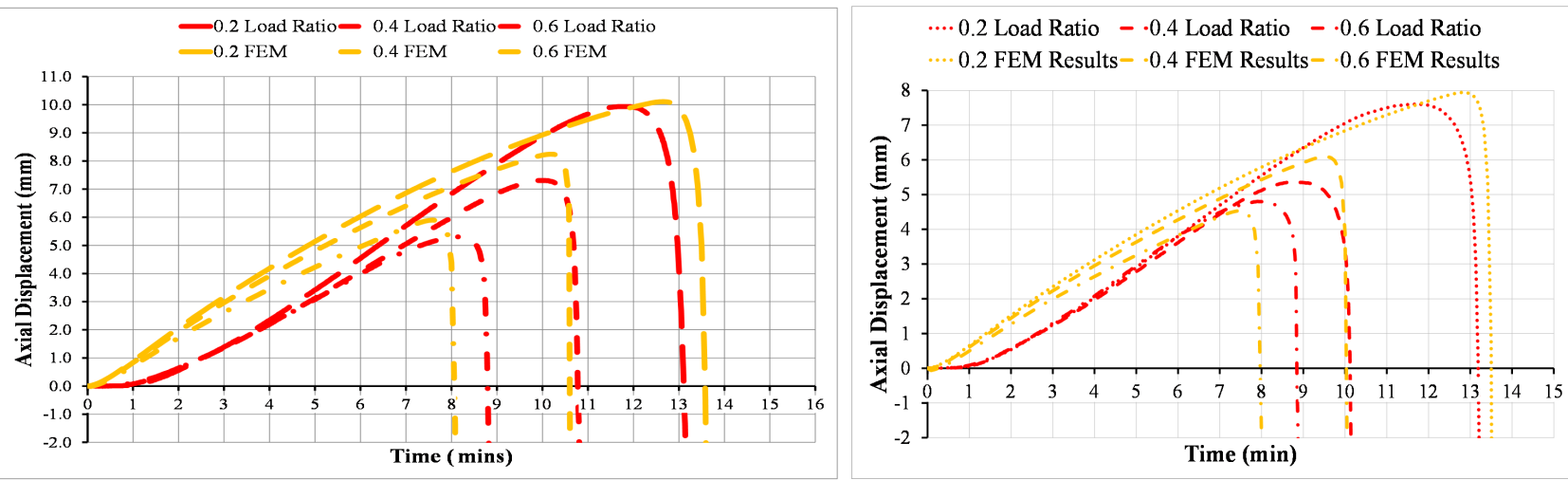

Figure 10. Development of Experimental and FEM axial displacements for unrestrained columns EHS, (left) EHS-A, (right) EHS-B.
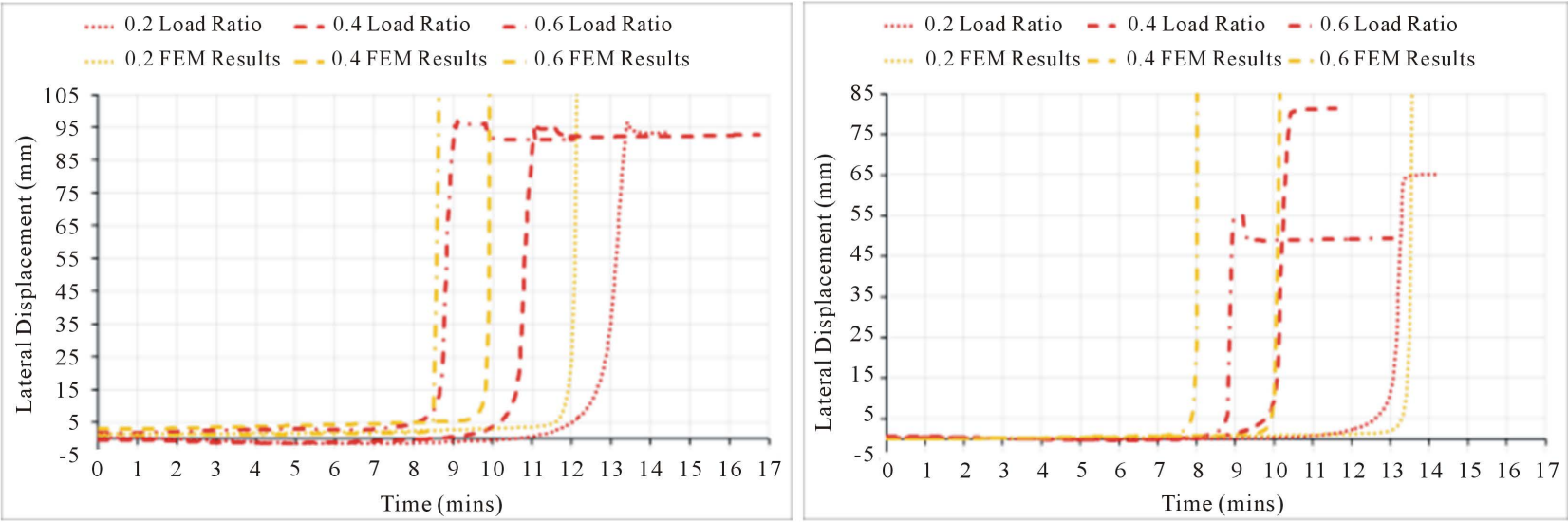

Figure 11. Development of Experimental and FEM lateral displacements for unrestrained columns EHS, (left) EHS-A, (right) EHS-B.

results are shown in Table 3 for the restraint scenario. It can be seen that there is an excellent agreement between the tests and the FEM in regards to the failure time and maximum displacements with some small divergence seen when the load increases to 0.6 of the ultimate load.

It was noted that the model failure occurs rather rapidly once the maximum displacement was reached in comparison to the test columns where failure was gradual. The results for the restraint case showed excellent correlation between the test and FEM in the failure time and maximum axial displacement and excellent agreement of the failure mechanism.

\section{Parametric Analysis}

With the model verified by the test results a parametric analysis has been carried out. The analysis studied the effect of different load levels, of varying slenderness values 60,90 and 120 on uniformly heated sections. The maximum load for each of the columns was calculated using EC3 method and an initial imperfection of $\mathrm{L} / 360$ was applied to each of the columns. The result from the analysis for $\lambda=90$ is shown in Figure 13 with the summary shown in Figure 14; which shows that 

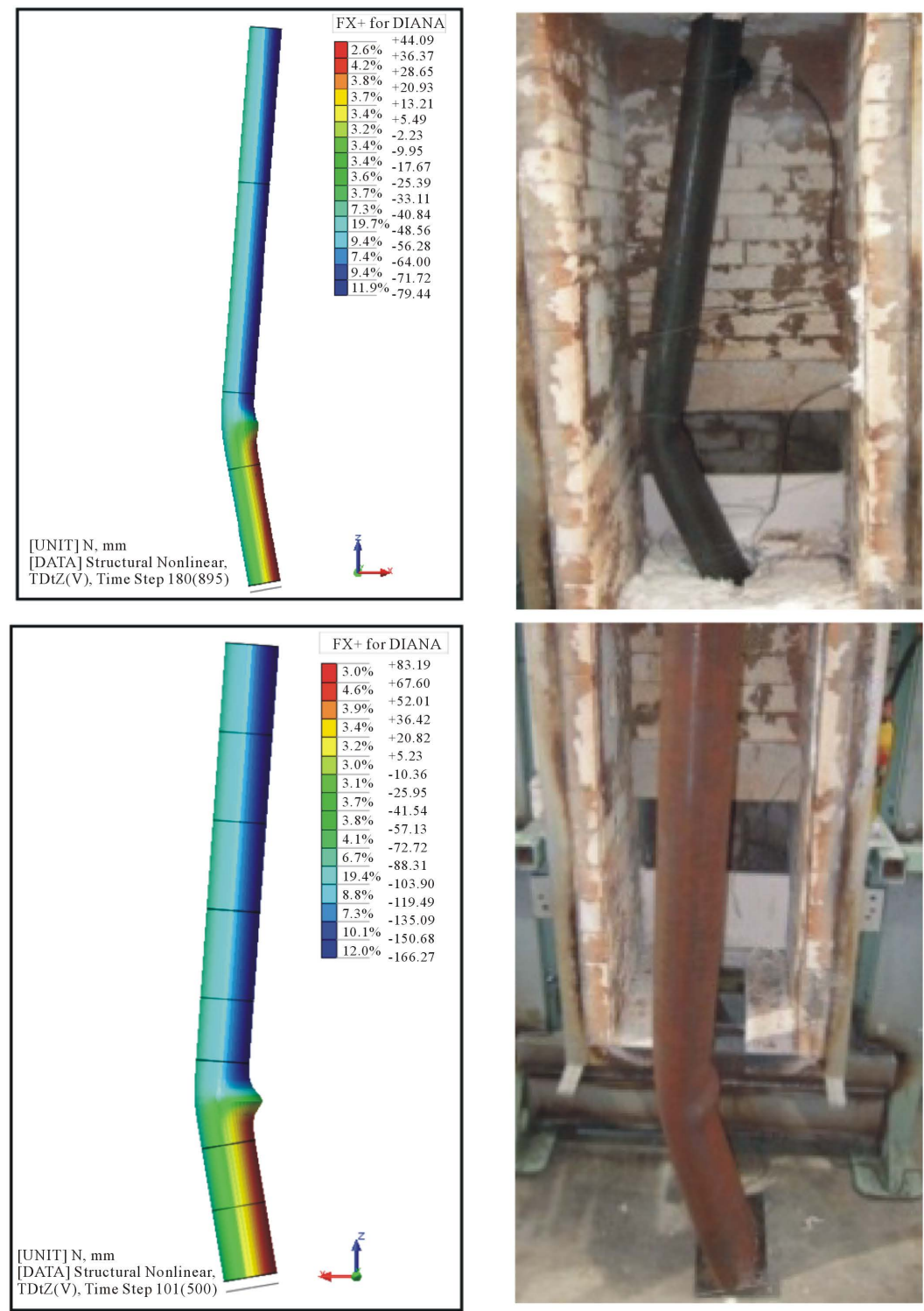

Figure 12. Experimental and FEM overall failure mechanism, (left) EHS-A, (right) EHS-B.

Table 3. Summary of results for FEM and experiment for restrained columns.

\begin{tabular}{|c|c|c|c|c|c|c|c|c|}
\hline \multirow{3}{*}{ Section } & \multirow{3}{*}{$\begin{array}{l}\text { Load } \\
\text { Ratio }\end{array}$} & \multirow{3}{*}{$\begin{array}{l}\text { Degree of Axial } \\
\text { Restraint }\end{array}$} & \multirow{2}{*}{\multicolumn{2}{|c|}{$\begin{array}{l}\text { Maximum Displacement } \\
(\mathrm{mm})\end{array}$}} & \multicolumn{4}{|c|}{ Time of Failure (mins) } \\
\hline & & & & & \multicolumn{2}{|c|}{ Axial } & \multicolumn{2}{|c|}{ Lateral } \\
\hline & & & FEM & Exp & FEM & Exp & FEM & Exp \\
\hline EHS-AR.0.2 & 0.2 & & 5.62 & 5.04 & 9 & 10 & 9 & 9 \\
\hline EHS-AR.0.4 & 0.4 & 0.12 & 4.67 & 4.04 & 7 & 8 & 7 & 7 \\
\hline EHS-AR.0.6 & 0.6 & & 2.99 & 2.47 & 6 & 5 & 5 & 5 \\
\hline EHS-BR 0.2 & 0.2 & & 5.31 & 3.93 & 9 & 10 & 9 & 9 \\
\hline EHS-BR 0.4 & 0.4 & 0.16 & 4.48 & 3.27 & 7 & 9 & 7 & 8 \\
\hline EHS-BR 0.6 & 0.6 & & 3.30 & 2.04 & 6 & 8 & 6 & 8 \\
\hline
\end{tabular}




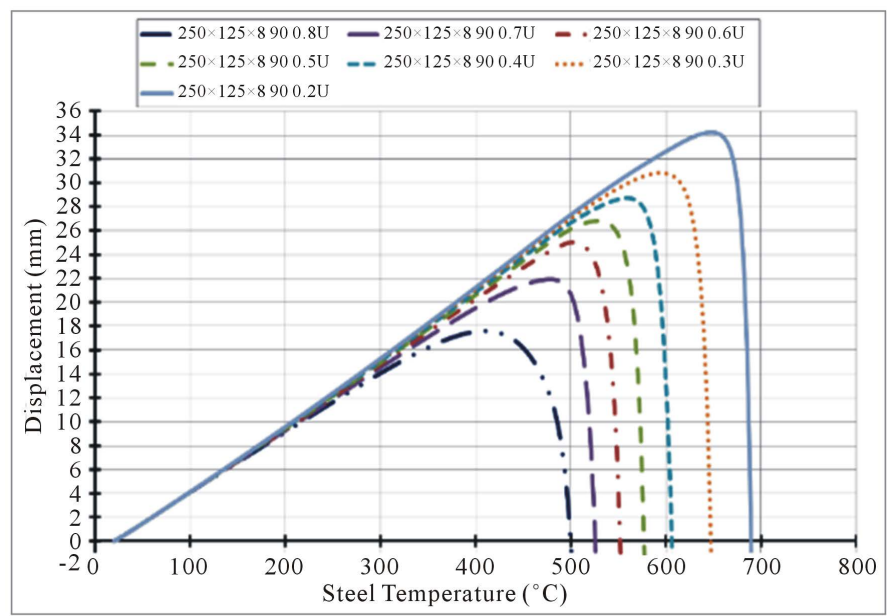

Figure 13. Results of parametric analysis for EHS-B for $\lambda=90$.

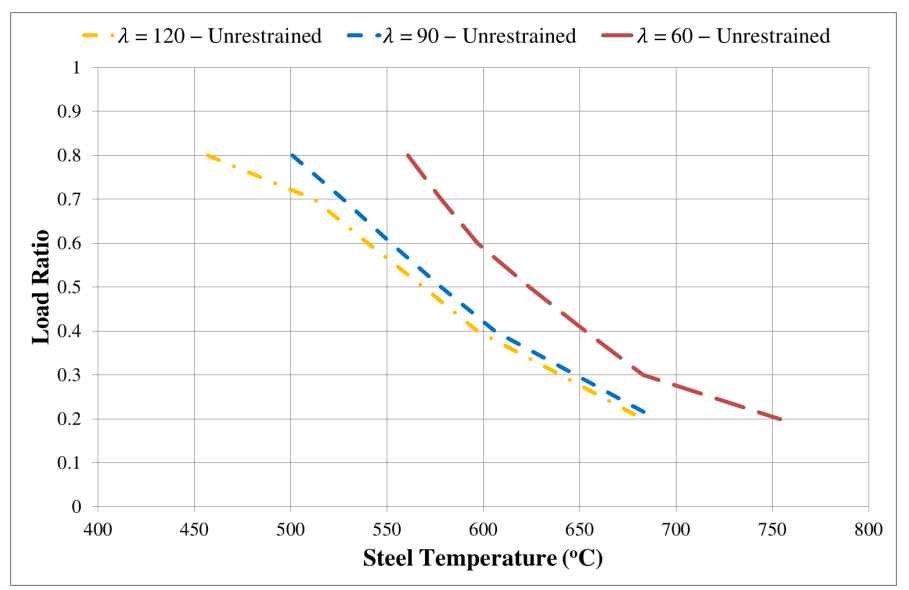

Figure 14. Summary of results of parametric analysis for EHS-B for varying slenderness and load ratio.

the more slender the column is the lower the failure temperature is for the section. Figure 13 shows also that increasing the loading level from 0.2 to 0.8 has reduced the maximum displacement by $47 \%$ and decreased the failure temperature by $28 \%$.

Figure 14 clearly shows a non-linear relationship between the loading ratio and the slenderness of the elliptical columns. In slenderness range of 90 to 120 the effect of loading on failure temperature is less than that in the range of 60 to 90. However in loading levels higher than $70 \%$ the reduction in failure temperatures is more significant in columns with slenderness around 120 .

The other factor investigated parametrically is the effect of restraint on the axial displacement of the columns. Figure 15 presents a relationship between axial displacement of restrained and unrestrained columns for two slenderness ratios 51 and 33. Figure 15, clearly shows a decrease in the axial displacement if axial restraint is imposed on columns. This conclusion is valid for both slenderness values of the column where similar pattern of behaviour is observable. 
The effect of restraint and loading on failure time of columns was also investigated. Figure 16 shows a reduction in failure time and fire resistance of columns subject to restraint axially. The conclusion can be drawn for both slenderness values involved.

Figure 17 shows the effect of slenderness on generated restraint forces in the
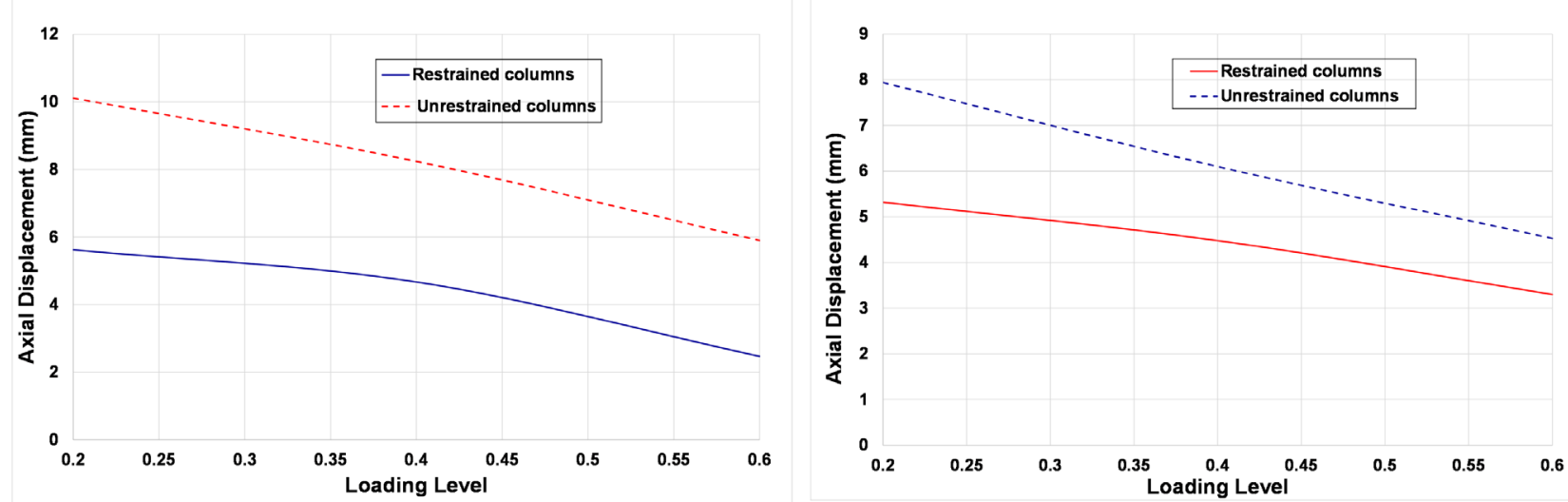

Figure 15. Effect of restraint on axial maximum displacement of columns, (left) slenderness $\lambda=51$, (right) slenderness $\lambda=33$.
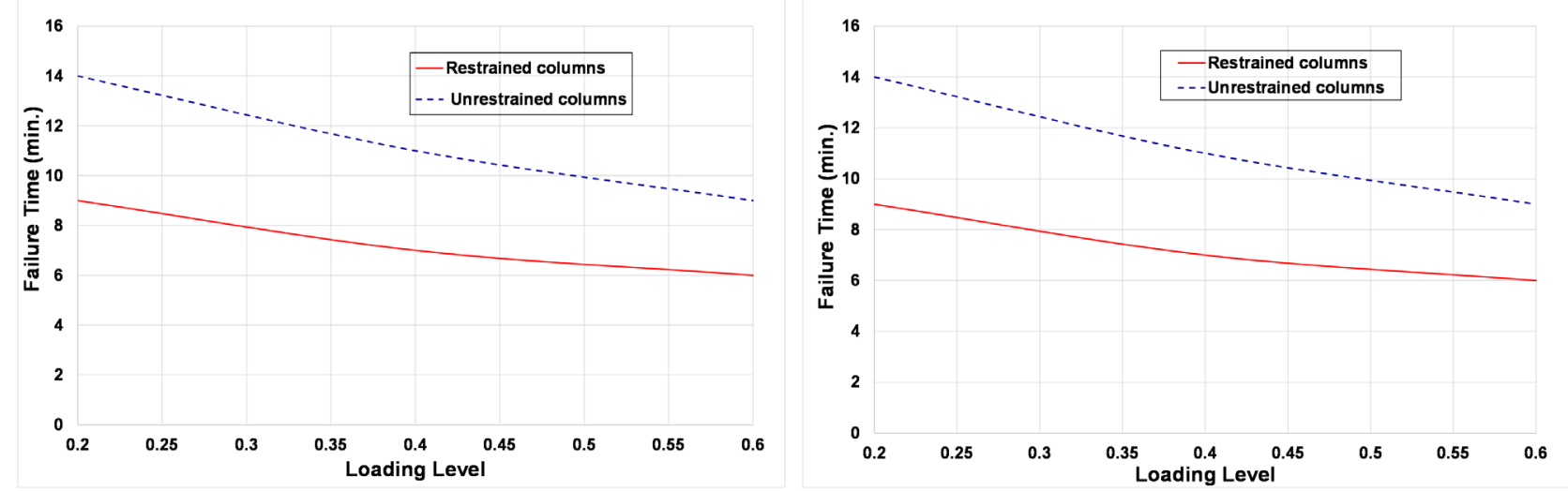

Figure 16. Effect of restraint on failure time of columns, (left) slenderness $\lambda=51$, (right) slenderness $\lambda=33$.

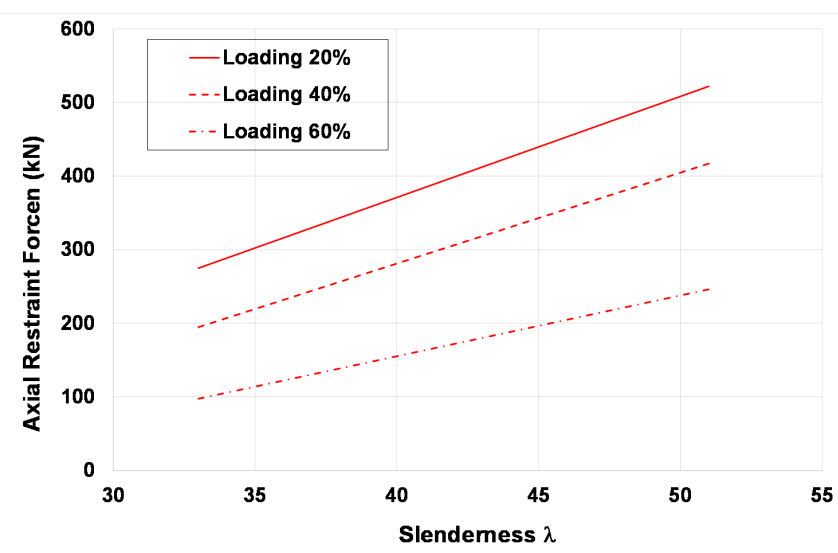

Figure 17. Effect of slenderness and loading on axially generated forces under fire. 
column under three loading ratios. The figure shows an increase in axial restraint forces generated under low slenderness i.e. the stockier the column is the higher the axial restraint forces. The values of the axial forces increase if the applied loading is decreased. All relationships are approximately linear.

\section{Conclusion}

The study has demonstrated that the maximum axial displacement of columns is less in the restraint tests compared to the unrestrained column. However, the maximum restraint force generated is greater when the load ratio is low. The study demonstrated that the failure of all columns can be by combination of overall and localised buckling occurring in the steel section where failure time decreased more as the loading level was increased. This is more evident in the larger section sizes. It was observed that by using variable with temperature thermal expansion coefficient and the EC3 thermal parameters, the FE model demonstrated reasonably good agreement with the experimental values of temperatures and excellent prediction of the mode of instability. The model has shown excellent agreements in failure modes of overall and local buckling. The study also highlighted the criticalness of the effect of geometric imperfections on the ultimate failure time and the fire resistance of the EHS column. The verified finite element model was used to conduct a parametric analysis involving parameters of loading level, restraint and slenderness. The parametric analysis has shown that the more slender the column, the lower the failure temperature. The parametric study has also shown a non-linear relationship between the loading ratio and the slenderness of the elliptical columns. Increasing the loading level from 0.2 to 0.8 has reduced the maximum displacement by $47 \%$ and decreased the failure temperature by $28 \%$. In columns' slenderness range of 90 to 120 , the effect of loading on failure temperature is less than that in the range of 60 to 90 . It also showed a decrease in the axial displacements of columns if an axial restraint is imposed. The analysis has shown that increasing the loading decreases the axial displacement under fire and reduces the failure time of columns. The analysis also shows that the stockier the column is, the higher the generated axial restraint forces in fire.

\section{Acknowledgements}

The authors would like to thank the EPSRC (Engineering and Physical Sciences Research Council) UK for providing the funding grant EP/H048782/1 for this research.

\section{References}

[1] Gardner, L. and Chan, T.M. (2007) Cross-Section Classification of Elliptical Hollow Sections. Steel and Composite Structures, 7, 185-200. https://doi.org/10.12989/scs.2007.7.3.185

[2] Gardner, L. and Chan, T.M. (2009) Structural Design Rules for Elliptical Hollow 
Sections. 12 th International Symposium on Tubular Structures, 323-329.

[3] Gardner, L. and Ministro, A. (2005) Structural Steel Oval Hollow Sections. Structural Engineer, 83, 32-36.

[4] Chan, T.M. and Gardner, L. (2008) Compressive Resistance of Hot-Rolled Elliptical Hollow Sections. Engineering Structure, 30, 522-532. https://doi.org/10.1016/j.engstruct.2007.04.019

[5] Zhu, J.-H. and Young, B. (2012) Design of Cold-Formed Steel Oval Hollow Section Columns. Journal of Constructional Steel Research, 71, 26-37. https://doi.org/10.1016/j.jcsr.2011.11.013

[6] Scullion, T., Ali, F. and Nadjai, A. (2011) Effect of Axial Restraint on the Performance of Elliptical Hollow Section Steel Columns, in Hydrocarbon Fire. Engineering Structures, 33, 3155-3161. https://doi.org/10.1016/j.engstruct.2011.08.005

[7] Scullion, T., Ali, F. and Nadjai, A. (2011) Experimental Study on Performance of Elliptical Section Steel Columns under Hydrocarbon Fire. Journal of Constructional Steel, 67, 986-991. https://doi.org/10.1016/j.jcsr.2011.01.010

[8] Faris, A., Nadjai, A. and Goodfellow, N. (2016) Experimental and Numerical Study on the Performance of Hollow and Concrete-Filled Elliptical Steel Columns Subjected to Severe Fire. Fire and Materials, 40, 635-652.

https://doi.org/10.1002/fam.2316

[9] Espinos, A., Romero, M.L. and Hospitaler, A. (2013) Fire Design Method for Bar-Reinforced Circular and Elliptical Concrete Filled Tubular Columns. Engineering Structures, 56, 384-395. https://doi.org/10.1016/j.engstruct.2013.05.026

[10] Espinos, A., Gardner, L., Romero, M.L. and Hospitaler, A. (2011) Fire Behaviour of Concrete Filled Elliptical Steel Columns. Thin-Walled Structures, 49, 239-255. https://doi.org/10.1016/j.tws.2010.10.008

[11] Eurocode 1 (2002) BS EN 1991-1-2. Eurocode 1. Actions on Structures. General Actions. Actions on Structures Exposed to Fire, 2002.

[12] Eurocode 3 (2005) BS EN 1993-1-1. Eurocode 3. Design of Steel Structures. General Rules and Rules for Buildings.

[13] Eurocode 3 (2005) National Annex to Eurocode 3. Design of Steel Structures. General Rules and Rules for Buildings.

[14] TNO Building and Construction Research (2011) DIANA Finite Element Analysis User Manuals, Release 9.4.3, Delft. 